\title{
Ataxia-hypogonadism-choroidal dystrophy syndrome
}

INSERM

\section{Source}

INSERM. (1999). Orphanet: an online rare disease and orphan drug data base. Ataxiahypogonadism-choroidal dystrophy syndrome. ORPHA:1180

Ataxia-hypogonadism-choroidal dystrophy syndrome is a very rare autosomal recessive, slowly progressive neurodeg enerative disorder characterized by the triad of cerebellar ataxia (that generally manifests at adolescence or early adulthood), chorioretinal dystrophy, which may have a later onset (up to the fifth-sixth decade) leading to variable degrees of visual impairment, and hypogonadotropic hypogonadism (delayed puberty and lack of secondary sex characteristics). Ataxia-hypogonadism-choroidal dystrophy syndrome belongs to a clinical continuum of neurodegenerative disorders along with the clinically overlapping cerebellar ataxia-hypogonadism syndrome (see this term). 